\title{
Strategy of constructing virtual peaking unit by public buildings' central air conditioning loads for day-ahead power dispatching
}

\author{
Chenxing YANG ${ }^{1}$, Qingshan XU ${ }^{1}$, Xufang WANG ${ }^{1}$
}

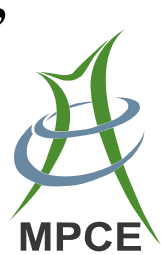

\begin{abstract}
With the gradually widely usage of the air conditioning (AC) loads in developing countries, the urban power grid load has swiftly increased over the past decade. Especially in China, the AC load has accounted for over $30 \%$ of the maximum load in many cities during summer. This paper proposes a scheme of constructing a virtual peaking unit (VPU) by public buildings' cool storage central AC (CSCAC) systems and non-CSCAC (NCSCAC) systems for the day-ahead power network dispatching (DAPND). Considering the accumulation effect of different meteorological parameters, a short term load forecasting method of public building's central AC (CAC) baseline load is firstly discussed. Then, a second-order equivalent thermal parameters model is established for the public building's CAC load. Moreover, the novel load reduction control strategies for the public building's CSCAC system and the public building's NCSCAC system are respectively presented. Furthermore, based on the multiple-rank control strategy, the model of the DAPND with the participation of a VPU is set up. The VPU is composed of large-scale
\end{abstract}

CrossCheck date: 18 October 2016

Received: 20 May 2016/Accepted: 18 October 2016/Published online: 20 January 2017

(C) The Author(s) 2017. This article is published with open access at Springerlink.com

$\triangle$ Qingshan XU

xuqingshan@seu.edu.cn

Chenxing YANG

chenxing_yang88@126.com

Xufang WANG

wang.xu.fang@163.com

1 Department of Electrical Engineering, Southeast University, Nanjing 210096, China regulated public building's CAC loads. To demonstrate the effectiveness of the proposed strategy, results of a sample study on a region in Nanjing which involves 22 public buildings' CAC loads are described in this paper. Simulated results show that, by adopting the proposed DAPND scheme, the power network peak load in the region obviously decreases with a small enough deviation between the regulated load value and the dispatching instruction of the VPU. The total electricity-saving amount accounts for $7.78 \%$ of total electricity consumption of the VPU before regulation.

Keywords Central air conditioning, Peak load shedding, Day-ahead power network dispatching, Virtual peaking unit, Schedulable capacity

\section{Introduction}

In China, with the development of social economy and the raise of people's living standard, the total grid load is increasing rapidly and the peak-valley difference of grid load is widening continuously. For most areas of China, the maximum grid load appears in the high temperature period in summer. Taking Jiangsu province as an example, affected by the extremely warm weather, the maximum grid load was 81.41 million kilowatts on July $25^{\text {th }}, 2013$, among which the maximum air conditioning (AC) load was above 25 million kilowatts accounting for more than $30 \%$ of the maximum total load. In order to meet the growing load demand, more than one hundred billion yuan (RMB) is invested for the construction of peaking power plants every year in China. However, the annual utilization hours of the peaking demand-oriented generation and transmission equipment is small and the average generation cost of the peaking unit is high. As a result, if the grid peak load is 
met solely by the increase of installed power-generation capacity, the power generation and supply cost would constantly increase. Therefore, due to the large proportion of AC load of the total grid load in summer, it is an effective way for releasing the conflict between power supply and power demand by constructing the large-scale AC loads as a virtual peaking unit (VPU) for load shedding in peak load period in summer.

Extensive research work has been performed to discuss the modeling, control strategies and schedulable potential of AC loads for peak load reduction in the past decades [1-15]. Based on the widely used equivalent thermal parameters (ETP) model for a decentralized AC load, a comfort-constrained state-queueing model is adopted to model and control the aggregated thermostatically controlled appliances in [16, 17]. Bashash et al. [18] develops a bilinear partial differential equation model and a sliding mode controller for the real-time management of thermostatic AC loads. Zhang et al. [19] builds a highly accurate aggregated model for a heterogeneous population of AC loads and designs a novel aggregated control strategy for the load population under realistic conditions. To provide a daily control scheduling, the dynamic programming algorithm is presented and optimized for groups of interruptible AC loads [20-22].To avoid the transient payback load phenomenon, a group-direct load control (DLC) program of air-conditioning systems is proposed with a least enthalpy estimator-based thermal comfort controller [23]. Goel et al. [24] provides a fuzzy logic based DLC scheme for AC loads which can achieve a good tradeoff among peak load shaving, system operating cost reduction and system reliability improvement. A decentralized control approach is proposed in [25] for accurate modulation of the aggregate power consumption of the thermostatically controlled loads. In order to manage a virtual power plant composed of a large number of customers with thermostatically controlled appliances, Ruiz et al. [26] provides a control strategy based not only on ON/OFF cycles but also on modifications of the temperature settings of the thermostats. Taking the customer's satisfaction into consideration, Huang et al. [27] presents a novel adaptive control strategy for integrating DLC with interruptible load management to provide instantaneous reserves for ancillary services. In order to eliminate the unwanted power oscillations, several safe protocols of the thermostatically controlled loads are presented for providing power system reserves [28, 29]. By utilizing the building simulation tool, the potential for residential mechanical pre-cooling of building thermal mass to shift the peak load is evaluated [30]. A Kalman filter-based method is proposed for estimating the energy savings of populations of controlled AC loads [31]. An evaluation performed by employing the energy management and control system of several control strategies is presented for split heating, ventilation and AC systems [32].

Only the decentralized AC loads of residential or public buildings are discussed in the literatures above. Comparing with the decentralized AC loads, the central AC (CAC) loads of public buildings tend to be more efficient for centralized regulation and also have great peak shaving potentialities. However, the specific DLC strategy of CAC loads for peak load reduction has rarely been addressed in the existing studies. Also, the model of power network dispatching with the participation of large-scale CAC loads has never been set up in the previous research. Therefore, based on the proposed load reduction control strategies for the CAC systems, the strategy of constructing a VPU by large-scale public building's non-cool storage CAC (NCSCAC) and cool storage CAC (CSCAC) loads for dayahead power network dispatching (DAPND) will mainly be studied in this paper.

The work of this paper is as follows. Firstly, a short term load forecasting method of public building's CAC baseline load will be discussed in Section 2. Then, a second-order ETP model of public building's CAC load will be established concerning the parameters of building in Section 3. Next, the load reduction control strategies for the public building's CSCAC and NCSCAC system will be presented respectively in Section 4. Also, the schedulable capacity of CAC system will be calculated by adopting the proposed control strategies. Furthermore, based on a proposed multiple-rank control pattern for the CAC system, the model of DAPND with the participation of a VPU which is composed of large-scale public building's CAC loads will be set up in Section 5 . Finally, a case study on a region in Nanjing which involves the public buildings of various industry types will be presented in Section 6 .

\section{Forecast of public building's CAC baseline load}

In this paper, the CAC baseline load of each public building which is the important parameter for establishing the decision model of the DAPND in the following sections needs to be firstly forecasted. Thus, a short term load forecasting method for public building's CAC load is presented in this section considering the accumulation effect of meteorological parameters.

Firstly, by calculating the Pearson's similarity degree, the correlativity between public building's CAC load and different meteorological parameters of temperature, humidity, wind velocity and rainfall are respectively 
analyzed. The calculation formula of Pearson's correlation coefficient can be written as [33]:

$$
r=\frac{\sum_{i=1}^{N}\left(x_{i}-\bar{x}\right)\left(y_{i}-\bar{y}\right)}{\sqrt{\sum_{i=1}^{N}\left(x_{i}-\bar{x}\right)^{2} \sum_{i=1}^{N}\left(y_{i}-\bar{y}\right)^{2}}}
$$

where $x_{i}$ is the meteorological parameter value for each sampling hour; $\bar{x}$ is the average value of all the $x_{i} ; y_{i}$ is the public building's CAC load for each sampling hour (kW); $\bar{y}$ is the average value of all the $y_{i}(\mathrm{~kW}) ; N$ is the total number of the sampling hours, which is taken as 24 .

According to the Pearson's similarity theory, $x$ has the strong correlation with $y$ when $|r|$ is greater than $0.7 ; x$ has the general correlation with $y$ when $|r|$ is from 0.4 to 0.7 ; $x$ has the weak correlation with $y$ when $|r|$ is smaller than 0.4. Taking the public buildings' CAC load in a region of the city of Nanjing as an example, the Pearson's correlation coefficients between public building's CAC load and different meteorological parameters for every hour from June $15^{\text {th }}$ to September $15^{\text {th }}$ of 2013 are calculated as follows: (a) For the meteorological parameter of temperature, $r$ equals 0.758; (b) For the meteorological parameter of humidity, $r$ equals -0.704 ; (c) For the meteorological parameter of atmospheric pressure, $r$ equals -0.344 ; (d) For the meteorological parameter of wind velocity, $r$ equals 0.189 ; (e) For the meteorological parameter of rainfall, $r$ equals -0.207 . It can be seen that, the meteorological parameter of temperature and humidity have the strong correlation with the public building's CAC load. Therefore, these two meteorological parameters are selected to participate in the short term load forecasting for public building's CAC baseline load.

Furthermore, considering the accumulation effect of both temperature and humidity to the forecast of public building's CAC load, the meteorological index of Weighted Temperature and Humidity Index (WTHI) is taken for participating in the load forecasting. This meteorological index is adopted by the PJM's electricity market in the United States and its definition can be expressed as [34]:

$K_{\mathrm{WTHI}}=\left(10 \times K_{\mathrm{THI}}+K_{\mathrm{THI},-1}+K_{\mathrm{THI},-2}\right) / 14$

$K_{\mathrm{THI}}=T_{\mathrm{F}}+\left(0.55-0.55 H_{\mathrm{L}}\right) \times\left(T_{\mathrm{F}}-58\right)$

where $K_{\mathrm{WTHI}}$ is the Weighted Temperature and Humidity Index of the sampling day; $K_{\mathrm{THI}}, K_{\mathrm{THI}-1}$ and $K_{\mathrm{THI}-2}$ are respectively the temperature and humidity index (THI) of the sampling day, the day before the sampling day and 2 days before the sampling day; $T_{\mathrm{F}}$ is the average Fahrenheit temperature of the sampling day; $H_{\mathrm{L}}$ is the humidity of the sampling day (\%). The absolute values of error between the $K_{\mathrm{WTHI}}$ of the forecasted day and the
$K_{\mathrm{WTHI}}$ of the days within two months before the forecasted day are respectively calculated. Twenty days with the minimum absolute values of error are selected as the typically similar day.

Finally, the back propagation neural network (BPNN) is adopted. For this BPNN, the input variables are $K_{\mathrm{THI}}$ and $K_{\mathrm{WTHI}}$ and the output variables are 96 public building's CAC load values for each regulation period of a day (A day is divided into 96 regulation periods whose duration is $15 \mathrm{~min}$ in this paper. In addition, assume that the values of all the power variables and cooling capacity variables discussed in this paper remain constant in each regulation period). By using the values of the input and output variables of the 20 typically similar days, the connection weights between the hidden layer and the output layers for the BPNN are determined. Then, based on these connection weights, the 96 public building's CAC load values for the forecasted day are acquired by inputting the values of its $K_{\mathrm{THI}}$ and $K_{\mathrm{WTHI}}$.

To verify the forecast precision, the load forecasting method is firstly adopted to obtain the baseline load values of one public building's CAC system in Nanjing on July $30^{\text {th }}, 2013$. After comparing the 96 forecasted load values with the actual load values, the average error ratio which equals $3.52 \%$ is small enough for the DAPND in the following sections. Thus, in this paper, the short term load forecasting method above is applied to acquire the baseline load of each studied public building's CAC system in peak load shaving period (PLSP).

\section{Modeling of public building's CAC load}

Usually, a set of CAC system is employed as the cooling system of public building, which mainly includes one or more chiller units, the corresponding number of chilled water pumps, cooling water pumps and cooling towers and the terminal equipment of fan coil units, fresh air units and climatic conditioning cabinets. The required cooling capacity of the building is all supplied by the chiller units. According to the law of conservation of energy, the sum of instantaneous gain of heat $q_{\mathrm{cl}}$, fresh air load $q_{\mathrm{nw}}$ and heat storage capacity of interior wall $q_{\mathrm{x}}$ is equal to cooling capacity of CAC system $q_{\mathrm{ch}} \cdot q_{\mathrm{cl}}$ is equal to the sum of hourly cooling load forming by the transient heat transfer from the exterior wall and roof $q_{\mathrm{er}}$, hourly cooling load forming by the transient heat transfer from the external window $q_{\mathrm{ew}}$, hourly cooling load forming by the radiant heat of the sun from the external window $q_{\mathrm{rh}}$, hourly cooling load forming by the heat dissipation of indoor electro thermal equipment $q_{\mathrm{e}}$, hourly cooling load 
forming by the heat dissipation of indoor lighting equipment $q_{1}$ and hourly cooling load forming by the heat dissipation of indoor human bodies $q_{\mathrm{p}}$. The expression of each variable can be written as:

$$
\begin{aligned}
& q_{\mathrm{ch}}=q_{\mathrm{cl}}+q_{\mathrm{nw}}+q_{\mathrm{x}} \\
& q_{\mathrm{cl}}=q_{\mathrm{er}}+q_{\mathrm{ew}}+q_{\mathrm{rh}}+q_{\mathrm{e}}+q_{1}+q_{\mathrm{p}} \\
& q_{\mathrm{er}}=\sum K_{\mathrm{i}} F_{\mathrm{i}}\left(T_{\text {out }}-T_{\mathrm{in}}\right) \\
& q_{\mathrm{ew}}=\sum K_{\mathrm{c}} F_{\mathrm{c}}\left(T_{\text {out }}-T_{\mathrm{in}}\right) \\
& q_{\mathrm{rh}}=\sum q_{\mathrm{f}} F_{\mathrm{c}} C_{\mathrm{s}} C_{\mathrm{n}} C_{\mathrm{cl}} \\
& q_{\mathrm{e}}=1000 n_{1} n_{2} n_{3} N_{\mathrm{e}} \\
& q_{1}=1000 n_{4} n_{5} n_{6} n_{7} N_{\mathrm{l}} \\
& q_{\mathrm{p}}=C_{\mathrm{r}} n_{\mathrm{p}} \phi q_{\mathrm{r}}+n_{\mathrm{p}} \phi q_{\mathrm{q}} \\
& q_{\mathrm{nw}} \approx 1.01 G_{\mathrm{k}}^{\mathrm{n}} T_{\text {out }}-1.01 G_{\mathrm{k}}^{\mathrm{n}} T_{\mathrm{in}}+38.5 G_{\mathrm{k}}^{\mathrm{n}} \\
& q_{\mathrm{x}}=S_{\mathrm{i}} F_{\mathrm{in}} \mathrm{d} T_{\mathrm{in}}(t)
\end{aligned}
$$

where $F_{\mathrm{i}}$ is the area of the interior wall or roof $\left(\mathrm{m}^{2}\right) ; K_{\mathrm{i}}$ is the heat transfer coefficient of the interior wall or roof (W/ $\left.\left(\mathrm{m}^{2} \cdot \mathrm{K}\right)\right) ; T_{\text {in }}$ is the indo or design temperature $\left({ }^{\circ} \mathrm{C}\right) ; F_{\mathrm{c}}$ is the area of the external window $\left(\mathrm{m}^{2}\right) ; K_{\mathrm{c}}$ is the heat transfer coefficient of the external window $\left(\mathrm{W} /\left(\mathrm{m}^{2} \cdot \mathrm{K}\right)\right) ; T_{\text {out }}$ is the outdoor air temperature $\left({ }^{\circ} \mathrm{C}\right) ; q_{\mathrm{f}}$ is the maximum radiant heat of the sun from the external window $\left(\mathrm{W} / \mathrm{m}^{2}\right) ; C_{\mathrm{s}}$ is the correction coefficient of the glass type of the external window; $C_{\mathrm{n}}$ is the shading coefficient of the inner curtain of the external window; $C_{\mathrm{cl}}$ is the cooling load coefficient of the external window; $n_{1}$ is the setting coefficient of the indoor electro thermal equipment; $n_{2}$ is the load factor of the indoor electro thermal equipment; $n_{3}$ is the load simultaneity of the indoor electro thermal equipment; $N_{\mathrm{e}}$ is the installation power of the indoor electro thermal equipment $(\mathrm{kW}) ; n_{4}$ is the load simultaneity of the indoor lighting equipment; $n_{5}$ is the heat storage coefficient of the indoor lighting equipment; $n_{6}$ is the consumed power coefficient of the rectifier; $n_{7}$ is the setting coefficient of the indoor lighting equipment; $N_{1}$ is the installation power of the indoor lighting equipment $(\mathrm{kW}) ; C_{\mathrm{r}}$ is the cooling load coefficient of the sensible heat gain from human bodies; $n_{\mathrm{p}}$ is the total number of persons in the building; $q_{\mathrm{r}}$ is the sensible heat release of an adult man $(\mathrm{W}) ; \varphi$ is the clustering coefficient, which is the heat dissipation ratio of a man, a woman or a child converted into an adult man; $q_{\mathrm{q}}$ is the latent heat release of an adult man $(\mathrm{W}) ; G_{\mathrm{k}}^{\mathrm{n}}$ is the fresh air volume $(\mathrm{g} /$ $\mathrm{s}) ; S_{\mathrm{i}}$ is the heat storage coefficient of the interior wall (W/ $\left.\left(\mathrm{m}^{2} \cdot \mathrm{K}\right)\right) ; F_{\text {in }}$ is the area of the interior wall $\left(\mathrm{m}^{2}\right)$.
For a building, the indoor air thermal equilibrium equations during the cooling period and the outage period can be respectively expressed as:

$$
\begin{aligned}
& C_{\mathrm{a}} V_{\mathrm{k}} \rho_{\mathrm{a}} \mathrm{d} T_{\mathrm{in}}=q_{\mathrm{c} 1} \mathrm{~d} t+q_{\mathrm{nw}} \mathrm{d} t-q_{\mathrm{x}} \\
& C_{\mathrm{a}} V_{\mathrm{k}} \rho_{\mathrm{a}} \mathrm{d} T_{\text {in }}=q_{\mathrm{c} 1} \mathrm{~d} t+q_{\mathrm{nw}} \mathrm{d} t-q_{\mathrm{x}}-q_{\mathrm{ch}, t} \mathrm{~d} t
\end{aligned}
$$

where $C_{\mathrm{a}}$ is the air constant pressure specific heat $\left(\mathrm{J} / \mathrm{kg} \cdot{ }^{\circ} \mathrm{C}\right)$, which is taken as $0.28 ; V_{\mathrm{k}}$ is the volume of the refrigeration space of the building $\left(\mathrm{m}^{3}\right)$, which can be calculated by multiplying the usable area, story height and layer number; $\rho_{\mathrm{a}}$ is the air density $\left(\mathrm{kg} / \mathrm{m}^{3}\right)$, which is taken as $1.29 ; q_{\mathrm{ch}, t}$ is the hourly cooling capacity of the chiller units of the CAC system (W).

From (14) and (15), the thermodynamic equation of the public building's CAC system during the cooling period and the outage period can be given by

$X_{\mathrm{k}} \frac{\mathrm{d} T_{\text {in }}}{\mathrm{d} t}+B_{\mathrm{k}} T_{\text {in }}-A_{\mathrm{k}}=0$

$X_{\mathrm{k}} \frac{\mathrm{d} T_{\text {in }}}{\mathrm{d} t}+B_{\mathrm{k}} T_{\text {in }}-\left(A_{\mathrm{k}}-q_{\mathrm{ch}, \mathrm{t}}\right)=0$

where

$$
\left\{\begin{array}{c}
A_{\mathrm{k}}=\sum K_{\mathrm{i}} F_{\mathrm{i}} T_{\text {out }}+\sum K_{\mathrm{c}} F_{\mathrm{c}} T_{\mathrm{out}}+q_{\mathrm{f}} F_{\mathrm{c}} C_{\mathrm{s}} C_{\mathrm{n}} C_{\mathrm{cl}} \\
+1000 n_{1} n_{2} n_{3} N_{\mathrm{e}}+1000 n_{4} n_{5} n_{6} n_{7} N_{\mathrm{l}} \\
+C_{\mathrm{r}} n \phi q_{\mathrm{r}}+n \phi q_{\mathrm{q}}+1.01 G_{\mathrm{k}}^{\mathrm{n}} T_{\mathrm{out}}+38.5 G_{\mathrm{k}}^{\mathrm{n}} \\
B_{\mathrm{k}}=\sum_{\mathrm{i}} F_{\mathrm{i}}+\sum K_{\mathrm{c}} F_{\mathrm{c}}+1.01 G_{\mathrm{k}}^{\mathrm{n}} \\
X_{\mathrm{k}}=C_{\mathrm{a}} V_{\mathrm{k}} \rho_{\mathrm{a}}+S_{\mathrm{i}} F_{\mathrm{in}}
\end{array}\right.
$$

Equations (16) and (17) constitute the modeling of the public building's CAC system.

\section{Load reduction control strategy of public building's CAC system}

\subsection{Control strategy for NCSCAC system}

According to (16) and (17), the variable of $t$ is discretized by taking $h$ as the time interval and assume that the chiller units of the CAC operate with the constant power $p_{\mathrm{ch}}$ (corresponding to the constant cooling capacity of the chiller units $q_{\mathrm{ch}}$, namely $q_{\mathrm{ch}, \mathrm{t}} \equiv q_{\mathrm{ch}}$ ) throughout the cooling period. Then, the relationship between the building's indoor temperature and the time during the cooling period and the outage period can be respectively written as: 
$T_{\text {in }}^{t+1}=c \cdot T_{\text {in }}^{t}+(1-c) \cdot D^{t+1}$

$T_{\mathrm{in}}^{t+1}=c \cdot T_{\mathrm{in}}^{t}+(1-c) \cdot\left(D^{t+1}-\frac{q_{\mathrm{ch}}}{B_{\mathrm{k}}}\right)$

where $c=\mathrm{e}^{-\frac{B_{\mathrm{k}}}{X_{\mathrm{k}}}} ; D=\frac{A_{\mathrm{k}}}{B_{\mathrm{k}}}$, which is related to the variable of $T_{\text {out }}$.

Assuming that $T_{\text {out }}$ is constant in a control period, the following equations can be achieved.

$\tau_{\text {off }}=\log _{c}\left(\frac{T_{\max }-D}{T_{\min }-D}\right) \cdot h$

$\tau_{\text {on }}=\log _{c}\left(\frac{T_{\min }-D+\frac{q_{\mathrm{ch}}}{B_{\mathrm{k}}}}{T_{\max }-D+\frac{q_{\mathrm{ch}}}{B_{\mathrm{k}}}}\right) \cdot h$

$\tau_{\mathrm{c}}=\tau_{\mathrm{on}}+\tau_{\mathrm{off}}$

where $\left[T_{\min } T_{\max }\right]$ is the control interval of the building's indoor temperature $\left({ }^{\circ} \mathrm{C}\right) ; \tau_{\mathrm{c}}$ is one start-stop control period of the chiller units of the building's CAC system (s). $\tau_{\text {on }}$ and $\tau_{\text {off }}$ are respectively the cooling period and the outage period of the chiller units of the CAC system in one control period (s). It can be seen from (20) to (22) that the cyclic variation between $T_{\min }$ and $T_{\max }$ (as shown in Fig. 1) of the building's indoor temperature can be realized when the chiller units operate with the constant cooling capacity $q_{\mathrm{ch}}$ for $\tau_{\text {on }}$ and stop working for $\tau_{\text {off }}$ in $\tau_{\mathrm{c}}$.

The screw-type or centrifugal chiller units are generally employed in the building's CAC system. Usually, for one chiller unit, the rated power is not less than $100 \mathrm{~kW}$ and the rated speed is not less than $3000 \mathrm{r} / \mathrm{min}$. Thus, the instantaneous startup and shutdown of each chiller unit cannot be implemented. Therefore, the frequent periodic start-stop control strategy above cannot be ideally achieved for the building's CAC system. In view of this, a novel control strategy for the public building's NCSCAC system by alternatingly and periodically opening and closing the terminal equipment of each floor is proposed in this paper. On the premise of satisfying the thermal comfort requirement, the strategy can not only achieve the load reduction of public building's NCSCAC system, but also make the chiller units operating under the ideal working state. The control strategy is applied on the basis of two assumptions below: (a) Under the identical

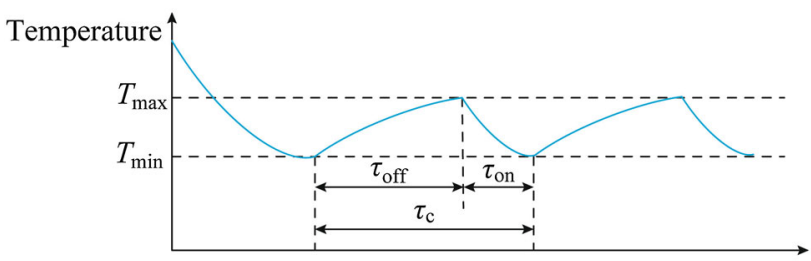

Time $(\min )$

Fig. 1 Cyclic variation of the building's indoor temperature working state of terminal equipment, the cooling capacity of the chiller units evenly distributes on each floor of a building; (b) Under the same initial condition of indoor temperature, the variation of room temperature for each floor of a building is equal in any time period when equal cooling capacity is acquired. For the control strategy, on one hand, the chiller units of building's NCSCAC system operate with the constant cooling capacity $\bar{q}_{\mathrm{ch}}$ throughout the cooling period. Also, $\bar{q}_{\mathrm{ch}}$ satisfies (20), (21), (22) and the following formulas.

$$
\begin{aligned}
& \begin{cases}\frac{n}{2} \cdot \tau_{\mathrm{on}}=\frac{n}{2} \cdot \tau_{\mathrm{off}} & \\
\bar{q}_{\mathrm{ch}}=\frac{n}{2} \cdot q_{\mathrm{ch}} & n \text { is even }\end{cases} \\
& \begin{cases}\frac{n-1}{2} \cdot \tau_{\mathrm{on}}=\frac{n+1}{2} \cdot \tau_{\mathrm{off}} & \\
\bar{q}_{\mathrm{ch}}=\frac{n+1}{2} \cdot q_{\mathrm{ch}} & n \text { is odd }\end{cases}
\end{aligned}
$$

where $n$ is the number of stories of the building. On the other hand, the terminal equipment of each floor of a building opens for $\tau_{\text {on }}$ and close for $\tau_{\text {off periodically and }}$ alternatingly. Take $n$ as 10 for example, the specific regulation strategy is shown in Fig. 2 when $n$ is even. In one control period $\tau_{\mathrm{c}}$, the combination of open and closed state of the terminal equipment for each floor is different in each time step, whose duration is $2 \tau_{\mathrm{on}} / n$. From one time step to another, the terminal equipment of one floor must be closed to stop cooling this story and the terminal equipment of another floor must be reopened correspondingly. As a result, in every time step, the number of stories whose terminal equipment is in open state is $n / 2$, which is equal to those in closed state. By adopting this control strategy, the chiller units of building's NCSCAC system operate with the constant cooling capacity $\bar{q}_{\text {ch }}$ which satisfies (23) and (24) in a control period $\tau_{\mathrm{c}}$, meanwhile, the room temperature of each floor of a building remains cyclically varying between $T_{\min }$ and

\begin{tabular}{|c|c|c|c|c|c|c|c|c|c|c|c|}
\hline & \multicolumn{10}{|c|}{ Story number } \\
\hline & & 1 & 2 & 3 & 4 & 5 & 6 & 7 & 8 & 9 & 10 \\
\hline \multirow{10}{*}{ 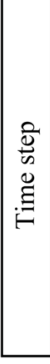 } & 1 & & & & & & & & & & \\
\hline & 2 & & & & & & & & & & \\
\hline & 3 & & & & & & & & & & \\
\hline & 4 & & & & & & & & & & \\
\hline & 5 & & & & & & & & & & \\
\hline & 6 & & & & & & & & & & \\
\hline & 7 & & & & & & & & & & \\
\hline & 8 & & & & & & & & & & \\
\hline & 9 & & & & & & & & & & \\
\hline & 10 & & & & & & & & & & \\
\hline
\end{tabular}
$T_{\max }$. The control mode is similar when $n$ is odd.

Fig. 2 Control strategy for terminal equipment of building's NCSCAC system 
According to (23) and (24), the differences are that the duration of each time step in one control period is $2 \tau_{\text {on }}$ l $(n+1)$ and the number of stories whose terminal equipment is in open state is $(n+1) / 2$ in every time step.

The centrifugal chiller compressor has high efficiency when operating at $40 \%-100 \%$ load and the phenomenon of 'surge' is more likely to occur when it works under $40 \%$ load. Meanwhile, the efficiency of screw-type chiller compressor may sharply decrease while running under $50 \%$ load. Therefore, by adopting the proposed control strategy, each chiller unit of the building's NCSCAC system is assigned to operate at the load not less than $40 \%$.

\subsection{Control strategy for CSCAC system}

The chiller units of public building's CSCAC system include the dual-operation chiller units and the base chiller units. Generally, the operation mode of the public building's CSCAC system without regulation is as follows. At 0:00 a.m. to 8:00 a.m. when the valley electricity price is applied, the dual-operation chiller units operate at the rated power and the acquired cold energy is stored in the ice-storage tank, meanwhile, the cooling load for the building's indoor temperature decrease is all supplied by the base chiller units. At 8:00 a.m. to 12:00 p.m., the cooling load for the building's indoor temperature decrease is preferentially provided by the base chiller units and the residual part which cannot be supplied by the base chiller units is provided by the stored ice in the ice-storage tank.

By adopting the operation mode above, the problem that the stored cold energy in ice-storage tank cannot all or nearly all be released in a day is caused, which results in the waste of energy. In view of this, a constant ratio control method for the regulation of public building's CSCAC system is employed in this paper. The specific control strategy is as follows. At 0:00 a.m. to 8:00 a.m., the operation mode of public building's CSCAC system remains unchanged. At 8:00 a.m. to 12:00 p.m., the cooling load for the building's indoor temperature reduction is jointly supplied by the base chiller units and the ice-storage tank and the ratio of the cooling capacity provided by the ice-storage tank to the whole cooling capacity for the building's indoor temperature decrease is a constant value $k$. The control method can not only realize the whole or nearly whole release of the stored cold in ice-storage tank in a day by selecting an appropriate value of $k$, but also achieve the load reduction of public building's CSCAC system in peak load period. The control method can be expressed as:

$q_{i}=q_{\mathrm{b}, i}+q_{\mathrm{s}, i}$ $q_{\mathrm{s}, i}=k \cdot q_{i}$

$\frac{1}{4} \sum_{i=33}^{96} q_{\mathrm{s}, i}=\left(1-K_{\mathrm{LF}}\right) \cdot Q_{\mathrm{s}}$

where $i$ is the regulation period, $i=33,34, \ldots, 96 . q_{i}$ is the total cooling capacity for the building's indoor temperature reduction in the period of $i(\mathrm{~kW}) ; q_{\mathrm{b}, i}$ is the cooling capacity provided by the base chiller units in the period of $i(\mathrm{~kW}) ; q_{\mathrm{s}, i}$ is the cooling capacity supplied by the icestorage tank in the period of $i(\mathrm{~kW}) ; K_{\mathrm{LF}}$ is the percentage of residual ice amount in the ice-storage tank at the end of the day; $Q_{\mathrm{s}}$ is the total stored cold energy supplied by the dual-operation chiller units from 0 a.m. to 8 a.m. (kWh).

\subsection{Calculation of schedulable capacity of public building's CAC system}

By employing the control strategies above, the chiller units of building's CAC system may operate at part load conditions. For the crew-type and centrifugal chiller units discussed in this paper, the electricity consumption has a nonlinear relationship with the cooling capacity of one chiller unit. On the basis of the parameters of each chiller unit provided by the manufacturer, the nonlinear relationship between the electricity consumption and the cooling capacity of each chiller unit can be fitted into the following cubic polynomial form.

$$
\begin{aligned}
p_{\mathrm{c}, f, g, i}= & d_{3, f, g} \cdot q_{\mathrm{c}, f, g, i}^{3}+d_{2, f, g} \cdot q_{\mathrm{c}, f, g, i}^{2}+d_{1, f, g} \cdot q_{\mathrm{c}, f, g, i} \\
& +d_{0, f, g}
\end{aligned}
$$

where $q_{\mathrm{c}, f, g, i}$ is the cooling capacity of the $g^{\text {th }}$ chiller unit of the $f^{\text {th }}$ public building in the period of $i(\mathrm{~kW}) ; p_{\mathrm{c}, f, g, i}$ is the electricity consumption of the $g^{\text {th }}$ chiller unit of the $f^{\text {th }}$ public building in the period of $i(\mathrm{~kW}) ; d_{3, f, g}, d_{2, f, g}, d_{1, f, g}$ and $d_{0, f, g}$ are all the part load fitting coefficient of the $g^{\text {th }}$ chiller unit of the $f^{\text {th }}$ public building.

From (28), the total load value of each public building's CAC system by adopting the proposed control strategy above can be calculated. Then, the schedulable capacity of each public building's CAC system can be written as:

$p_{\mathrm{d}, f, i}=p_{f, i}-p_{\mathrm{t}, f, i}$

where $p_{\mathrm{t}, f, i}$ is the total load value of the $f^{\text {th }}$ public building's CAC system after regulation in the period of $i(\mathrm{~kW})$, which equals to the sum of electricity consumption of the building's chiller units, chilled water pumps, cooling water pumps, cooling towers and terminal equipment; $p_{f, i}$ is the forecasted baseline load value of the $f^{\text {th }}$ public building's CAC system in the period of $i(\mathrm{~kW})$ by adopting the load forecasting method in Section 2; $p_{\mathrm{d} f, i}$ is the schedulable capacity of the $f^{\text {th }}$ public building's CAC system by 


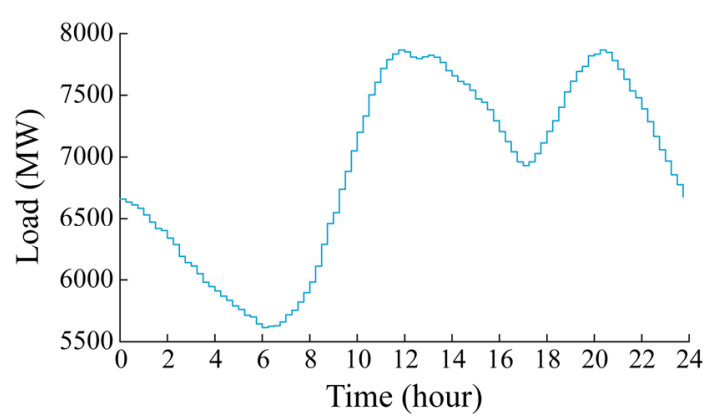

Fig. 3 Power network load of Nanjing of a typical day in summer

applying the proposed control strategy in the period of $i(\mathrm{~kW})$.

\section{Model of DAPND with participation of a VPU composed of large-scale public buildings' CAC loads}

Figure 3 shows the power network load curve of Nanjing during a typical day in summer in 2013. It can be seen that the morning peak load and the evening peak load respectively turn up at around 12:00 a.m. and 8:00 p.m. every day. Therefore, the period from 11:00 a.m. to 1:30 p.m. and the period from 7:30 p.m. to 9:00 p.m. are respectively selected as the morning and evening PLSP for the DAPND in this paper. The variety of the outdoor air temperature $T_{\text {out }}$ within each PLSP is small. Thus, in order to improve the engineering practicability of the proposed regulation strategy in this section, assume that $T_{\text {out }}$ is a constant value in each PLSP and the average value of $T_{\text {out }}$ during each PLSP is taken as the constant value.

In this section, the public buildings' CAC loads under DLC are involved in the power system operation. The largescale public buildings' NCSCAC and CSCAC loads which participate in the peak load shedding for the DAPND in the regulated region are considered as a VPU. The total load curtailment of these public buildings' CAC loads can be equivalent to the output of the VPU. Therefore, in this paper, the research on the combinatorial regulation of the largescale public buildings' CAC loads is for the achievement of the day-ahead VPU scheduling. The target of the day-ahead power network peak load regulation with the participation of the VPU in this paper is to realize the minimization of total operation cost of generating units (GUs) and VPU in the region. The target is on the premise of the small enough deviation between the regulated total load value and the dispatching instruction of the regional power grid in every PLSP. Meanwhile, the operation constraints of the GUs, the thermal comfort requirement for NCSCAC system and the requirement of the residual ice amount in ice-storage tank for CSCAC system are all satisfied after the regulation.
Based on the regulation target above, a multiple-rank control pattern for CAC system is adopted in this paper which offers three rank control schemes for each public building's CAC system. By applying this control pattern, three rank schedulable capacities of each building's CAC load in the PLSP are determined by setting the related parameter of the load reduction control strategy which is proposed in Section 4. The specific multiple-rank control method is as follows:

1) According to (20) and (21), the multiple-rank control method for NCSCAC system can be achieved by setting the different control intervals of the building's indoor temperature $\left[T_{\min } T_{\max }\right]$. ASHRAE standard recommends that the indoor temperature range which meet the human comfort requirement in summer is [24 27] ${ }^{\circ} \mathrm{C}$. Therefore, [23 26] ${ }^{\circ} \mathrm{C},[2327]^{\circ} \mathrm{C}$ and $[2328]^{\circ} \mathrm{C}$ are set to be the three rank control intervals of the public building's indoor temperature in this paper. From (20), (21), (23) and (24), these three rank control intervals of the indoor temperature respectively correspond to the three rank cooling capacities of the building's chiller units $\bar{q}_{\mathrm{ch}}$ in each PLSP.

2) According to (27), the multiple-rank control method for CSCAC system can be achieved by setting the different percentages of residual ice amount in the icestorage tank at the end of the day $K_{\mathrm{LF}}$. The constant ratio control method employed for the regulation of public building's CSCAC system requires the small enough residual ice amount in the ice-storage tank at the end of the day. Therefore, $0 \%, 2 \%$ and $4 \%$ are set to be the three rank values of $K_{\mathrm{LF}}$ in this paper. From (26) and (27), these three rank values of $K_{\mathrm{LF}}$ respectively correspond to the three constant values of $k$.

The target of the DAPND in this paper is to achieve the minimization of the system operation costs which includes the generation and start-up costs of GUs, environmental pollution governance costs brought by power generation and the compensation costs for all the regulated CAC systems in the region. Thus, the objective function of the decision model of DAPND with the participation of the VPU composed of large-scale public building's CAC loads can be expressed as:

$\min \left\{\begin{array}{l}{\left[\begin{array}{l}\sum_{i=45}^{54}\left(\sum_{f=1}^{F_{1}} \sum_{l=1}^{3} v_{\mathrm{m}, f} c_{\mathrm{com}} u_{\mathrm{m}, f, l} p_{\mathrm{d} f, l, i}+\sum_{f=F_{1}+1}^{F} \sum_{l=1}^{3} v_{\mathrm{m}, f} c_{\mathrm{com}} u_{f, l} p_{\mathrm{d}, f, l, i}\right) \\ +\sum_{i=79}^{84}\left(\sum_{f=1}^{F_{1}} \sum_{l=1}^{3} v_{\mathrm{e}, f} c_{\mathrm{com}} u_{\mathrm{e}, f, l} p_{\mathrm{d}, f, l, i}+\sum_{f=F_{1}+1}^{F} \sum_{l=1}^{3} v_{\mathrm{e}, f} c_{\mathrm{com}} u_{f, l} p_{\mathrm{d}, f, l, i}\right)\end{array}\right]} \\ +\sum_{i=1}^{96} \sum_{m=1}^{M}\left(c_{\mathrm{g}, m, i}+c_{\mathrm{st}, m, i}+e_{m} c_{\mathrm{em}} p_{\mathrm{g}, m, i}\right)\end{array}\right.$

where $v_{\mathrm{m}, f}$ and $v_{\mathrm{e}, f}$ are respectively the indicator variables donating whether the $f^{\text {th }}$ public building is open or not in the morning and evening PLSP (1 represents being open 
and 0 represents not); $c_{\text {com }}$ is the compensation electricity price for the public building whose CAC system participates in the peak load reduction (yuan/kWh); $u_{\mathrm{m}, f, l}$ and $u_{\mathrm{e}, f, l}$ are respectively the indicator variables donating whether the NCSCAC system of the $f^{\text {th }}$ public building employs the $l^{\text {th }}$ rank control pattern or not in the morning and evening PLSP; $u_{f, l}$ is the indicator variable donating whether the CSCAC system of the $f^{\text {th }}$ public building employs the $l^{\text {th }}$ rank control pattern or not; $p_{\mathrm{d} f, l, i}$ is the schedulable applying the $l^{\text {th }}$ rank control pattern in the period of $i(\mathrm{~kW})$, which can be calculated by (29); $F$ is the total number of the public buildings whose CAC system participate in the peak load shaving in the region; $F_{1}$ is the number of the public buildings which have the NCSCAC system for participating in the peak load shaving in the region; $c_{\mathrm{g}, m, i}$ is the generation cost of the $m^{\text {th }} \mathrm{GU}$ in the period of $i$ (yuan), which is a quadratic function of the output of the GU, namely $c_{\mathrm{g}, m, i}=h_{2, m} \cdot p_{\mathrm{g}, m, i}^{2}+h_{1, m} \cdot p_{\mathrm{g}, m, i}+h_{0, m} \cdot u_{m, i} ; p_{\mathrm{g}, m, i}$ is the output of the $m^{\text {th }} \mathrm{GU}$ in the period of $i(\mathrm{MW}) ; h_{2, m}$, $h_{1, m}$ and $h_{0, m}$ are all the generation cost characteristic coefficients of the $m^{\text {th }} \mathrm{GU} ; u_{m, i}$ is the indicator variables donating whether the $m^{\text {th }} \mathrm{GU}$ is open or not in the period of $i ; M$ is the total number of the GUs; $c_{\mathrm{st}, m, i}$ is the start-up costs of the $m^{\text {th }} \mathrm{GU}$ in the period of $i$ (yuan); $e_{m}$ is the per-unit pollutant discharge of the $m^{\text {th }} \mathrm{GU}$ (ton/MW); $c_{\mathrm{em}}$ is the governance price of the pollutant emitted by the GU (yuan/ton). The first term of (30) represents the sum of the compensation electricity bills for all the public buildings in the region in the PLSP, while the second term of (30) represents the sum of the generation and start-up costs of GUs and the environmental pollution governance costs in the region for all day.

The constraint conditions of this DAPND decision model can be given as follows:

1) In each regulation period, the sum of the outputs of all the GUs must equal to the difference between the total load value before regulation and the actual load reduction value of the VPU in the region, namely capacity of the $f^{\text {th }}$ public building's CAC system when

where $p_{\mathrm{t}, i}$ is the total load value of the region in the period of $i$ before regulation $(\mathrm{kW})$.

2) The maximum value of the deviation between the regulated total load value and the dispatching instruction of the VPU in the region in each PLSP of a day is limited as:

$\Delta p_{i}=\left\{\begin{array}{l}\left|p_{\mathrm{s}, i}-\left(\begin{array}{c}\sum_{f=1}^{F_{1}} \sum_{l=1}^{3} v_{\mathrm{m}, f} u_{\mathrm{m}, f, l} p_{\mathrm{t}, f, l, i} \\ +\sum_{f=F_{1}+1}^{F} \sum_{l=1}^{3} v_{\mathrm{m}, f} u_{f, l} p_{\mathrm{t}, f, l, i}\end{array}\right)\right| i=45,46, \ldots, 54 \\ \left|p_{\mathrm{s}, i}-\left(\begin{array}{c}\sum_{f=1}^{F_{1}} \sum_{l=1}^{3} v_{\mathrm{e}, f} u_{\mathrm{e}, f, l} p_{\mathrm{t}, f, l, i} \\ +\sum_{f=F_{1}+1}^{F} \sum_{l=1}^{3} v_{\mathrm{e}, f} u_{f, l} p_{\mathrm{t}, f, l, i}\end{array}\right)\right|\end{array}\right.$

$\max \left\{\Delta p_{i}\right\} \leq \Delta P \quad i=45,46, . ., 54,79,80, \ldots, 84$

where $\Delta p_{i}$ is the deviation between the regulated total load value and the dispatching instruction of the VPU in the region in the period of $i(\mathrm{~kW}) ; p_{\mathrm{t}, f, l, i}$ is the load value of the $f^{\text {th }}$ public building's CAC system by applying the $l^{\text {th }}$ rank control pattern in the period of $i(\mathrm{~kW}) ; p_{\mathrm{s}, i}$ is the dispatching instruction of the VPU in the region in the period of $i(\mathrm{~kW})$; $\Delta P$ is the permissible maximum value of the deviation.

3) The NCSCAC system of each public building must employ only one rank control pattern respectively throughout the morning and evening PLSP in a day, namely

$$
\begin{aligned}
& \sum_{l=1}^{3} u_{\mathrm{m}, f, l}=1 \\
& \sum_{l=1}^{3} u_{\mathrm{e}, f, l}=1
\end{aligned}
$$

$\sum_{m=1}^{M} p_{\mathrm{g}, m, i}=\left\{\begin{array}{cl}p_{\mathrm{t}, i} & i=1,2, \ldots, 44 \\ p_{\mathrm{t}, i}-\sum_{f=1}^{F_{1}} \sum_{l=1}^{3} v_{\mathrm{m}, f} u_{\mathrm{m}, f, l} p_{\mathrm{d}, f, l, i}-\sum_{f=F_{1}+1}^{F} \sum_{l=1}^{3} v_{\mathrm{m}, f} u_{f, l} p_{\mathrm{d}, f, l, i} & i=45,46, \ldots, 54 \\ p_{\mathrm{t}, i} & i=55,56, \ldots, 78 \\ p_{\mathrm{t}, i}-\sum_{f=1}^{F_{1}} \sum_{l=1}^{3} v_{\mathrm{e}, f} u_{\mathrm{e}, f, l} p_{\mathrm{d}, f, l, i}-\sum_{f=F_{1}+1}^{F} \sum_{l=1}^{3} v_{\mathrm{e}, f} u_{f, l} p_{\mathrm{d}, f, l, i} & i=79,80, \ldots, 84 \\ p_{\mathrm{t}, i} & i=85,86, \ldots, 96\end{array}\right.$ 
4) The CSCAC system of each public building must employ only one rank control pattern throughout a day, namely

$$
\sum_{l=1}^{3} u_{f, l}=1
$$

5) The output of each GU in each regulation period is limited as:

$u_{m, i} p_{\min , m} \leq p_{\mathrm{g}, m, i} \leq u_{m, i} p_{\max , m}$

where $p_{\min , m}$ and $p_{\max , m}$ are respectively the maximum and minimum generation power of the $m^{\text {th }} \mathrm{GU}(\mathrm{MW})$.

6) The up/down ramping rate of each GU is limited as:

$\left|p_{\mathrm{g}, m, i}-p_{\mathrm{g}, m, i-1}\right| \leq P_{\mathrm{r}, m} \cdot \Delta I \quad i=2,3, \ldots, 96$

where $P_{\mathrm{r}, m}$ is the ramp rate of the $m^{\text {th }} \mathrm{GU}(\mathrm{MW} / \mathrm{h}) ; \Delta I$ is the time interval of regulation (h), which is taken as 0.25 in this paper.

7) The minimum on-time and off-time of each GU are limited as:

$$
\begin{aligned}
& \left(u_{m, i-1}-u_{m, i}\right)\left(I_{m, i-1, \mathrm{on}}-I_{m, \text { min,on }}\right) \geq 0 \\
& \quad i=2,3, \ldots, 96 \\
& \left(u_{m, i}-u_{m, i-1}\right)\left(I_{m, i-1, \mathrm{off}}-I_{m, \text { min,off }}\right) \geq 0 \\
& \quad i=2,3, \ldots, 96
\end{aligned}
$$

where $I_{m, i-1, \text { on }}$ and $I_{m, i-1, \text { off }}$ are respectively the accumulated runtime and downtime of the $m^{\text {th }} \mathrm{GU}$ in the period of $i-1(\mathrm{~h}) ; I_{m, \text { min,on }}$ and $I_{m, \text { min,off }}$ are respectively the minimum continuous runtime and downtime of the $m^{\text {th }} \mathrm{GU}(\mathrm{h})$.

The (30) to (40) constitute the model of DAPND with the participation of large-scale public buildings' CAC loads, which is a single-objective mixed-integer nonlinear programming model with the decision variable of $\Gamma=$ $\left\{u_{\mathrm{m}, 1, l}, u_{\mathrm{m}, 2, l}, \ldots, u_{\mathrm{m}, F_{1}, l}, u_{\mathrm{e}, 1, l}, u_{\mathrm{e}, 2, l}, \ldots, u_{\mathrm{e}, F_{1}, l}, u_{F_{1}+1, l}, u_{F_{1}+2, l}, \ldots\right.$, $u_{F, l}, p_{\mathrm{g}, 1,1}, p_{\mathrm{g}, 1,2}, \ldots, p_{\mathrm{g}, 1,96}, p_{\mathrm{g}, 2,1}, p_{\mathrm{g}, 2,2}, \ldots, p_{\mathrm{g}, 2,96}, \ldots, p_{\mathrm{g}, M, 1}$, $\left.p_{\mathrm{g}, M, 2}, \ldots, p_{\mathrm{g}, M, 96}\right\}$. The programming model has a large number of decision variables, as a result, it will take hours to solve this optimization problem by employing the intelligent optimization algorithm, such as genetic algorithm, particle swarm algorithm and so on. In order to improve the computational efficiency, CPLEX optimization software package is considered to be adopted. CPLEX solution algorithms are designed to solve large, difficult problems quickly and are applicable for linear, quadratically constrained and mixed-integer programming problems. Among these equations, only (39) and (40) are formulated as nonlinear expressions which are not applicable to be solved by CPLEX solution algorithms. According to [35], both (39) and (40) can be changed into equivalent linear expressions. Then, the optimization

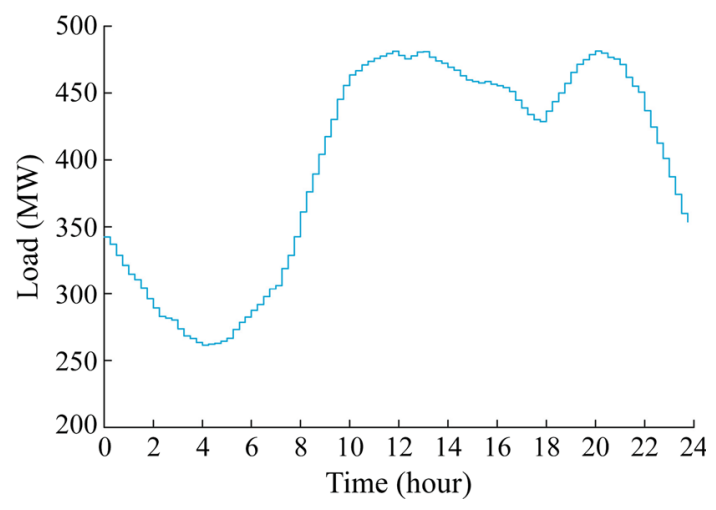

Fig. 4 Total forecasted load value of this region in each regulation period on July $30^{\text {th }}, 2013$

problem is transformed into a mixed-integer linear programming model and can be solved by CPLEX optimization software package easily. Only several minutes will be taken for running this optimization problem by applying CPLEX optimization software package.

\section{Case studies}

For further verification of the theoretical analysis, the DAPND scheme for peak load shedding of a region in Nanjing on July $30^{\text {th }}, 2013$ is discussed in this paper. The combinatorial regulation scheme of large-scale public buildings' CAC loads and the total peak load curtailment results are studied, also, the economy of the dispatching scheme is analyzed. The forecasted total load of the region on July $30^{\text {th }}, 2013$ is given in Fig. 4.

The studied region comprises the industrial district, the commercial district and the residential district. In this paper, the 22 public buildings in the commercial district whose total installed capacities of CAC systems are not less than $200 \mathrm{~kW}$ are selected to constitute a VPU for load reduction in the PLSPs. These 22 public buildings include 5 shopping malls (SMs), 13 office buildings (OBs) and 4 guest houses (GHs), among which \#5 SM, \#11 OB, \#12 OB, \#13 OB and \#4 GH employ the CSCAC system. $T_{\text {out }}$ is respectively 34.1 and $30.9^{\circ} \mathrm{C}$ in the morning and evening PLSP of this day. The day-ahead dispatching instructions of the VPU during the morning and evening PLSP $p_{\mathrm{s}, \mathrm{m}}$ and $p_{\mathrm{s}, \mathrm{e}}$ are respectively given as 23000 and $7820 \mathrm{~kW}$. The permissible maximum value of the deviation $\Delta P$ is set to be $35 \mathrm{~kW}$. Five GUs are employed for the power supply in the region. The parameters of each GU are given in Table 1 and the governance price for the pollutant emitted by the $\mathrm{GU}$ is 34.1 yuan/ton. In this paper, different compensation electricity prices are set to obtain the optimally combinatorial regulation scheme of public buildings' CAC loads. Due to the different thermal comfort level for each rank of 
Table 1 GU parameters

\begin{tabular}{|c|c|c|c|c|c|c|c|c|c|c|}
\hline Parameter & $c_{2}$ & $c_{1}$ & $c_{0}$ & $p_{\max }(\mathrm{MW})$ & $p_{\min }(\mathrm{MW})$ & $c_{\text {st }}($ yuan $)$ & $P_{\mathrm{r}}(\mathrm{MW} /$ hour $)$ & $I_{\min , \text { on }}($ hour) & $I_{\min , \text { off }}($ hour $)$ & $E(\operatorname{ton} / \mathrm{MW})$ \\
\hline \#1 GU & 0.00398 & 19.7 & 450 & 162 & 25 & 4340 & 81 & 2 & 2 & 0.82 \\
\hline \#2 GU & 0.00211 & 16.5 & 680 & 130 & 25 & 3472 & 65 & 2 & 2 & 0.78 \\
\hline \#3 GU & 0.00679 & 22.27 & 370 & 85 & 20 & 1550 & 63.75 & 1 & 1 & 0.63 \\
\hline \#4 GU & 0.00679 & 22.27 & 370 & 85 & 20 & 1550 & 63.75 & 1 & 1 & 0.63 \\
\hline \#5 GU & 0.00413 & 25.92 & 660 & 55 & 10 & 496 & 41.25 & 0.5 & 0.5 & 0.55 \\
\hline
\end{tabular}

Notes: $c_{2}, c_{1}$ and $c_{0}$ are all the generation cost characteristic coefficient of each $\mathrm{GU} ; p_{\max }$ and $p_{\min }$ are respectively the maximum and minimum generation power of each GU; $c_{\mathrm{st}}$ is the start-up cost of each GU; $P_{\mathrm{r}}$ is the ramp rate of each GU; $I_{\mathrm{min}, \text { on }}$ and $I_{\min , \text { off }}$ are respectively the minimum continuous runtime and downtime of each GU; $E$ is the per-unit pollutant discharge of each GU

the control patterns proposed in Section 5, the specific selection modes of control patterns for the public buildings which employ the NCSCAC system are as follows: (a) Only the first rank control pattern is considered to be employed when the compensation electricity price $c_{\text {com }}$ is set to be 0.3 yuan $/ \mathrm{kWh}$; (b) Both the first and the second rank control patterns are considered to be employed when $c_{\text {com }}$ is set to be 0.32 yuan $/ \mathrm{kWh}$; (c) All three ranks of control patterns are considered to be employed when $c_{\text {com }}$ is set to be 0.34 yuan $/ \mathrm{kWh}$.

Firstly, the total load values of each public building's CAC system are independently collected by the intelligent ammeter every 15 min within 2 months before July $30^{\text {th }}$, 2013. Then, based on the load forecasting method in Section 2, the baseline load values of each public building's
CAC system on July $30^{\text {th }}, 2013$ are acquired. Appendix of Tables A1 and A2 respectively display the forecasted load values of each public building's CAC system in the morning and evening PLSP of this day. Next, By adopting the load reduction control strategies of the public buildings' CAC systems proposed in Section 4 and the multiplerank control pattern for CAC system proposed in Section 5, the regulation parameters of each public building's CAC system in each PLSP can be calculated, as shown in Tables 2, 3 and 4.

The CPLEX optimization software package is adopted to solve the DAPND decision model proposed in Section 5 and the simulated results are as follows: (a) When $c_{\mathrm{com}}$ is 0.3 yuan $/ \mathrm{kWh}$, the maximum deviation between the regulated total load value and the dispatching instruction of the

Table 2 Regulation parameters of each public building's NCSCAC system in the morning PLSPs

\begin{tabular}{|c|c|c|c|c|c|c|}
\hline \multirow[t]{3}{*}{ Building } & \multicolumn{6}{|c|}{$\left[T_{\min } T_{\max }\right]\left({ }^{\circ} \mathrm{C}\right)$} \\
\hline & \multicolumn{2}{|c|}{$\left[\begin{array}{ll}23 & 26\end{array}\right]$} & \multicolumn{2}{|c|}{$\left[\begin{array}{ll}23 & 27\end{array}\right]$} & \multicolumn{2}{|c|}{$\left[\begin{array}{ll}23 & 28\end{array}\right]$} \\
\hline & $\tau_{\text {on }}$ & $\tau_{\text {off }}$ & $\tau_{\text {on }}$ & $\tau_{\text {off }}$ & $\tau_{\text {on }}$ & $\tau_{\text {off }}$ \\
\hline \#1 SM & 9.0 & 7.5 & 12.1 & 10.1 & 15.3 & 12.7 \\
\hline \#2 SM & 9.2 & 7.4 & 12.5 & 10.0 & 15.7 & 12.6 \\
\hline \#3 SM & 9.4 & 7.1 & 12.7 & 9.5 & 16.1 & 12.1 \\
\hline \#4 SM & 7.6 & 7.6 & 10.2 & 10.2 & 12.9 & 12.9 \\
\hline$\# 1 \mathrm{OB}$ & 14.7 & 14.7 & 19.8 & 19.8 & 25.0 & 25.0 \\
\hline$\# 2 \mathrm{OB}$ & 15.8 & 15.8 & 21.3 & 21.3 & 26.9 & 26.9 \\
\hline \#3 OB & 15.2 & 15.2 & 20.4 & 20.4 & 25.8 & 25.8 \\
\hline \#4 OB & 16.9 & 16.9 & 22.7 & 22.7 & 28.7 & 28.7 \\
\hline \#5 OB & 13.6 & 13.6 & 18.3 & 18.3 & 23.1 & 23.1 \\
\hline \#6 OB & 16.5 & 16.5 & 22.2 & 22.2 & 28.1 & 28.1 \\
\hline$\# 7 \mathrm{OB}$ & 16.4 & 16.4 & 22.1 & 22.1 & 27.9 & 27.9 \\
\hline \#8 OB & 18.5 & 17.1 & 24.9 & 23.0 & 31.4 & 29.0 \\
\hline \#9 OB & 21.9 & 19.2 & 29.5 & 25.8 & 37.3 & 32.7 \\
\hline \#10 OB & 15.9 & 15.9 & 21.4 & 21.4 & 27.0 & 27.0 \\
\hline$\# 1 \mathrm{GH}$ & 24.0 & 24.0 & 32.4 & 32.4 & 41.0 & 41.0 \\
\hline$\# 2 \mathrm{GH}$ & 23.5 & 23.5 & 31.7 & 31.7 & 40.1 & 40.1 \\
\hline$\# 3 \mathrm{GH}$ & 21.2 & 21.2 & 28.6 & 28.6 & 36.2 & 36.2 \\
\hline
\end{tabular}


Table 3 Regulation parameters of each public building's NCSCAC system in the evening PLSPs

\begin{tabular}{|c|c|c|c|c|c|c|}
\hline \multirow[t]{3}{*}{ Building } & \multicolumn{6}{|c|}{$\left[T_{\min } T_{\max }\right]\left({ }^{\circ} \mathrm{C}\right)$} \\
\hline & \multicolumn{2}{|c|}{$\left[\begin{array}{ll}23 & 26\end{array}\right]$} & \multicolumn{2}{|c|}{$\left[\begin{array}{ll}23 & 27\end{array}\right]$} & \multicolumn{2}{|c|}{$\left[\begin{array}{ll}23 & 28\end{array}\right]$} \\
\hline & $\tau_{\mathrm{on}}$ & $\tau_{\text {off }}$ & $\tau_{\mathrm{on}}$ & $\tau_{\text {off }}$ & $\tau_{\text {on }}$ & $\tau_{\text {off }}$ \\
\hline \#1 SM & 10.5 & 8.8 & 14.2 & 11.8 & 18.0 & 15.0 \\
\hline \#2 SM & 10.7 & 8.6 & 14.5 & 11.6 & 18.3 & 14.7 \\
\hline \#3 SM & 11.0 & 8.3 & 14.9 & 11.2 & 18.9 & 14.2 \\
\hline \#4 SM & 8.8 & 8.8 & 11.9 & 11.9 & 15.0 & 15.0 \\
\hline$\# 1 \mathrm{GH}$ & 26.3 & 26.3 & 35.5 & 35.5 & 44.9 & 44.9 \\
\hline \#2 GH & 24.5 & 24.5 & 33.1 & 33.1 & 41.9 & 41.9 \\
\hline$\# 3 \mathrm{GH}$ & 21.3 & 21.3 & 28.7 & 28.7 & 36.3 & 36.3 \\
\hline
\end{tabular}

Table 4 Regulation parameters of each public building's CSCAC system in each PLSP

\begin{tabular}{llll}
\hline Building & $k$ & & \\
\cline { 2 - 4 } & $K_{\mathrm{LF}}=0 \%$ & $K_{\mathrm{LF}}=2 \%$ & $K_{\mathrm{LF}}=4 \%$ \\
\hline \#5 SM & 0.416 & 0.408 & 0.400 \\
\#11 OB & 0.715 & 0.702 & 0.687 \\
\#12 OB & 0.615 & 0.603 & 0.591 \\
\#13 OB & 0.534 & 0.523 & 0.513 \\
\#4 GH & 0.371 & 0.364 & 0.356 \\
\hline
\end{tabular}

VPU in all the regulation periods $\Delta p_{\mathrm{m}}$ is larger than $35 \mathrm{~kW}$, in other words, the second constraint condition about $\Delta P$ of the decision model cannot be satisfied; (b) When $c_{\text {com }}$ is 0.32 yuan $/ \mathrm{kWh}, \Delta p_{\mathrm{m}}$ is equal to $34.7 \mathrm{~kW}$ and the system operation costs are given in Table 5; (c) When $c_{\text {com }}$ is 0.34 yuan $/ \mathrm{kWh}, \Delta p_{\mathrm{m}}$ is equal to $31.3 \mathrm{~kW}$ and the system operation costs are given in Table 6 . It can

Table 5 System operation costs when $c_{\text {com }}$ is 0.32 yuan $/ \mathrm{kWh}$ yuan

\begin{tabular}{lllll}
\hline$C_{1}$ & $C_{2}$ & $C_{3}$ & $C_{4}$ & $C_{\text {total }}$ \\
\hline 1447351.35 & 4092.00 & 1878.45 & 244700.40 & 1698022.20 \\
\hline
\end{tabular}

Notes: $C_{1}$ is the sum of the generation costs of GUs for all the day; $C_{2}$ is the sum of the start-up costs of GUs for all the day; $C_{3}$ is the environmental pollution governance costs brought by power generation for all the day; $C_{4}$ is the sum of the compensation costs for all the regulated $\mathrm{CAC}$ systems for all the day; $C_{\text {total }}$ is the total operation costs in the studied region for all the day

Table 6 System operation costs when $c_{\text {com }}$ is 0.34 yuan $/ \mathrm{kWh}$ yuan

\begin{tabular}{lllll}
\hline$C_{1}$ & $C_{2}$ & $C_{3}$ & $C_{4}$ & $C_{\text {total }}$ \\
\hline 1447349.94 & 4092.00 & 1998.80 & 244700.24 & 1698140.98
\end{tabular}

be seen that the total operation cost $C_{\text {total }}$ in (c) is slightly larger than that in (b), thus the impact of the variation of $c_{\text {com }}$ on the economy of DAPND can be ignored. Therefore, in order to make the regulated total load value of the VPU follow the dispatching instruction as well as possible in each PLSP, $c_{\text {com }}$ is set to be 0.34 yuan $/ \mathrm{kWh}$ in this paper. Table 7 shows the optimally combinatorial regulation scheme of public buildings' CAC loads when $c_{\text {com }}$ is 0.34 yuan $/ \mathrm{kWh}$. Figure 5 illustrates the comparison of the power network total load of the region before and after regulation during the morning PLSP. Figure 6 illustrates the comparison of the power network total load of the region before and after regulation during the evening PLSP. It can be observed from Figs. 5 and 6 that, by employing the proposed DAPND strategy, the power network peak load in the region obviously decreases. Tables 8 and 9 respectively display the total load before and after regulation and the electricity-saving amount of the VPU during the morning and evening PLSP. It can be seen that, the total electricity consumptions of the VPU in the region are respectively 75141.16 and $69299.30 \mathrm{kWh}$ before and after regulation during all the PLSPs for July $30^{\text {th }}, 2013$. Thus, the total electricity-saving amount $P_{\text {save }}$ is $5841.86 \mathrm{kWh}$ which accounts for $7.78 \%$ of the total electricity consumption of the VPU before regulation during all the PLSPs.

Table 7 Optimally combinatorial regulation scheme of public buildings' CAC loads

\begin{tabular}{lllllll}
\hline Building & $u_{\mathrm{m}, 1}$ & $u_{\mathrm{m}, 2}$ & $u_{\mathrm{m}, 3}$ & $u_{\mathrm{e}, 1}$ & $u_{\mathrm{e}, 2}$ & $u_{\mathrm{e}, 3}$ \\
\hline \#1 SM & 0 & 0 & 1 & 1 & 0 & 0 \\
\#2 SM & 0 & 0 & 1 & 1 & 0 & 0 \\
\#3 SM & 0 & 0 & 1 & 1 & 0 & 0 \\
\#4 SM & 0 & 0 & 1 & 1 & 0 & 0 \\
\#5 SM & 0 & 0 & 1 & 0 & 0 & 1 \\
\#1 OB & 1 & 0 & 0 & - & - & - \\
\#2 OB & 1 & 0 & 0 & - & - & - \\
\#3 OB & 1 & 0 & 0 & - & - & - \\
\#4 OB & 1 & 0 & 0 & - & - & - \\
\#5 OB & 1 & 0 & 0 & - & - & - \\
\#6 OB & 0 & 0 & 1 & - & - & - \\
\#7 OB & 0 & 0 & 1 & - & - & - \\
\#8 OB & 1 & 0 & 0 & - & - & - \\
\#9 OB & 0 & 0 & 1 & - & - & - \\
\#10 OB & 1 & 0 & 0 & - & - & - \\
\#11 OB & 1 & 0 & 0 & - & - & - \\
\#12 OB & 1 & 0 & 0 & - & - & - \\
\#13 OB & 1 & 0 & 0 & - & - & - \\
\#1 GH & 0 & 1 & 0 & 1 & 0 & 0 \\
\#2 GH & 0 & 0 & 1 & 1 & 0 & 0 \\
\#3 GH & 0 & 0 & 1 & 1 & 0 & 0 \\
\#4 GH & 0 & 0 & 1 & 0 & 0 & 1 \\
\hline
\end{tabular}




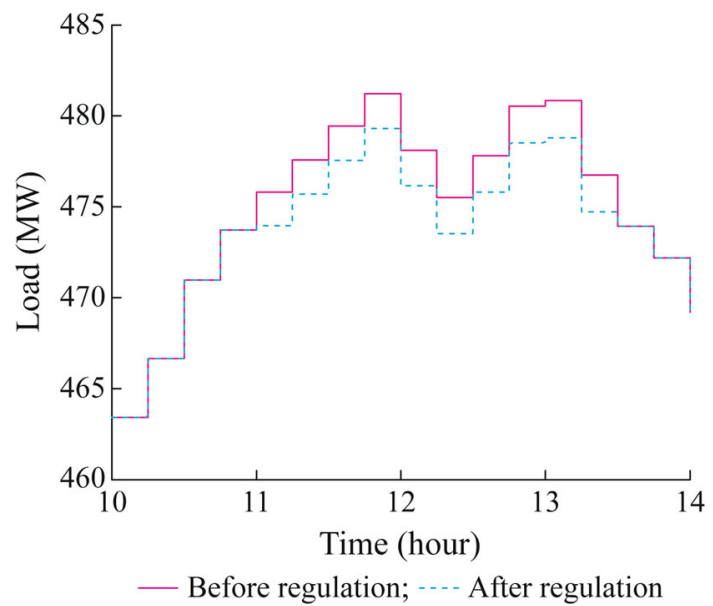

Fig. 5 Power network load of the region before and after regulation during morning PLSP

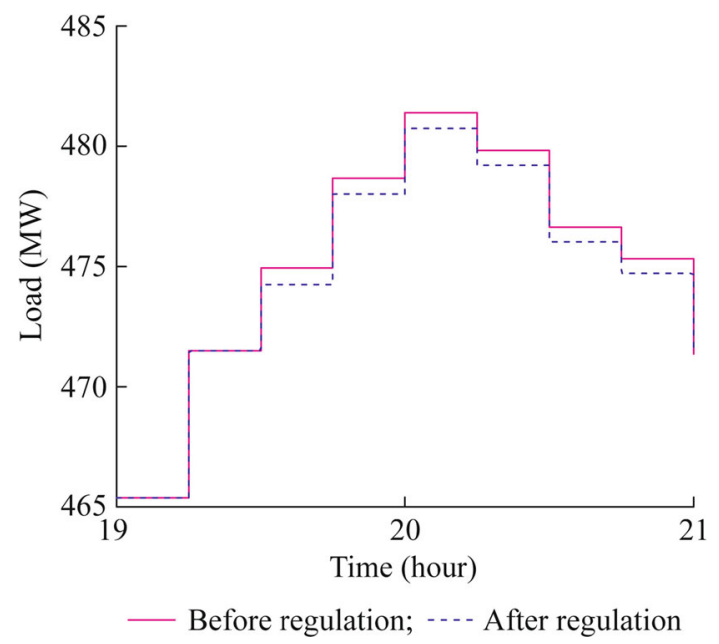

Fig. 6 Power network load of the region before and after regulation during evening PLSP

Table 8 Total load before and after regulation and the electricitysaving amount of the VPU during the morning PLSP

\begin{tabular}{llll}
\hline$i$ & $p_{U, i}(\mathrm{~kW})$ & $p_{t, U, i}(\mathrm{~kW})$ & $P_{\text {save }, i}(\mathrm{kWh})$ \\
\hline 45 & 24832.1 & 22989.44 & 460.67 \\
46 & 24859.2 & 22990.88 & 467.07 \\
47 & 24888.1 & 22993.45 & 473.67 \\
48 & 24922.5 & 22997.98 & 481.13 \\
49 & 24955.5 & 23003.77 & 487.92 \\
50 & 24989.2 & 23010.72 & 494.61 \\
51 & 25012.2 & 23016.25 & 498.99 \\
52 & 25039.7 & 23021.75 & 504.48 \\
53 & 25065.2 & 23027.28 & 509.48 \\
54 & 25052.9 & 23031.26 & 505.42 \\
\hline
\end{tabular}

Notes: $p_{U, i}$ is the total baseline load of the VPU before regulation in the regulation period of $i ; p_{t, U, i}$ is the total load of the VPU after regulation in the regulation period of $i ; P_{\mathrm{save}, i}$ is the electricity-saving amount of the VPU during the regulation period of $i$
Table 9 Total load before and after regulation and the electricitysaving amount of the VPU during the evening PLSP

\begin{tabular}{llll}
\hline$i$ & $p_{U, i}(\mathrm{~kW})$ & $p_{t, U, i}(\mathrm{~kW})$ & $P_{\text {save }, i}(\mathrm{kWh})$ \\
\hline 79 & 8535.70 & 7850.32 & 171.35 \\
80 & 8518.47 & 7854.13 & 166.09 \\
81 & 8506.14 & 7857.94 & 162.05 \\
82 & 8475.85 & 7854.14 & 155.43 \\
83 & 8460.41 & 7851.57 & 152.21 \\
84 & 8451.53 & 7846.31 & 151.31 \\
\hline
\end{tabular}

\section{Conclusion}

This work is devoted to study the strategy of constructing a VPU by large-scale public buildings' NCSCAC and CSCAC loads for participating in the DAPND. The works of the paper are summarized as follows:

1) By applying the Pearson's similarity theory, the meteorological parameters of temperature and humidity have been selected to participate in the load forecasting of CAC baseline load. Considering the accumulation effect of these two meteorological parameters, a short term baseline load forecasting method of public building's CAC load has been presented.

2) Based on the established second-order ETP model of public building's CAC load in this paper, a load reduction control strategy for public building's NCSCAC system by alternatingly and periodically opening and closing the terminal equipment of each floor and a constant ratio control method for load reduction of public building's CSCAC system have been proposed respectively. Both the operating efficiency of each chiller unit and the energy utilization efficiency have been concerned in these load reduction control strategies, also, these two strategies are easy to be operated in real application.

3) Multiple-rank control patterns for both NCSCAC and CSCAC load have been presented. On the basis of this control strategy, the model of the DAPND with the participation of a VPU which is composed of largescale public building's NCSCAC and CSCAC loads has been set up. Moreover, it is a single-objective mixed-integer nonlinear programming model which can be easily solved by applying the CPLEX optimization software package.

4) A case study on a region in Nanjing which involves the public buildings of various industry types has been presented to verify the proposed strategy on a typical day in summer. The optimally combinatorial 
regulation scheme of public buildings' NCSCAC and CSCAC loads have been discussed for the DAPND. Simulated results have shown that the power network peak load obviously decreases during the PLSP by adopting the proposed strategy. The total electricitysaving amount accounts for $7.78 \%$ of the total electricity consumption of the VPU before regulation during all the PLSPs. Also, the deviation between the regulated total load value and the dispatching instruction is within a reasonable range.

The work in this paper explores a DAPND scheme for peak load shedding by regulating the demand-side resources of public building's NCSCAC and CSCAC loads. The studied strategy can be extended to the nationwide applications; as a result, it will contribute to effectively alleviating the pressure of power network and reducing the environmental pollution in China.

In this paper, the decentralized AC load of the public building has not been discussed. Thus, the strategy of constructing a VPU by both public buildings' CAC loads and public buildings' decentralized AC loads will be developed in the further study.

Acknowledgements This work was supported by National Key Technology Support Program (No. 2013BAA01B00) and National Natural Science Foundation of China (No. 51361130152, No. 51577028).

Open Access This article is distributed under the terms of the Creative Commons Attribution 4.0 International License (http:// creativecommons.org/licenses/by/4.0/), which permits unrestricted use, distribution, and reproduction in any medium, provided you give appropriate credit to the original author(s) and the source, provide a link to the Creative Commons license, and indicate if changes were made.

\section{Appendix A}

See Tables A1 and A2.

Table A1 Baseline load values of each public building's CAC system before regulation in the morning PLSP on July $30^{\text {th }}, 2013$

\begin{tabular}{|c|c|c|c|c|c|c|c|c|c|c|}
\hline \multirow[t]{2}{*}{ Building } & \multicolumn{10}{|l|}{$p_{i}(\mathrm{~kW})$} \\
\hline & $i=45$ & $i=46$ & $i=47$ & $i=48$ & $i=49$ & $i=50$ & $i=51$ & $i=52$ & $i=53$ & $i=54$ \\
\hline \#1 SM & 1210.37 & 1211.24 & 1212.56 & 1213.12 & 1218.89 & 1225.12 & 1225.23 & 1226.01 & 1226.12 & 1225.38 \\
\hline \#2 SM & 1130.40 & 1131.22 & 1134.19 & 1137.76 & 1137.38 & 1138.52 & 1145.27 & 1144.31 & 1145.94 & 1148.09 \\
\hline \#3 SM & 928.66 & 929.58 & 930.75 & 932.82 & 935.98 & 938.30 & 940.80 & 944.80 & 946.03 & 944.40 \\
\hline \#4 SM & 1180.90 & 1181.70 & 1182.65 & 1183.71 & 1184.04 & 1186.82 & 1188.50 & 1189.35 & 1190.97 & 1189.60 \\
\hline \#5 SM & 1229.62 & 1230.35 & 1230.07 & 1229.57 & 1229.05 & 1229.63 & 1231.07 & 1230.35 & 1229.85 & 1229.47 \\
\hline \#1 OB & 1455.59 & 1458.91 & 1460.62 & 1468.81 & 1470.64 & 1473.07 & 1474.72 & 1475.44 & 1477.54 & 1475.84 \\
\hline \#2 OB & 1148.39 & 1150.91 & 1152.56 & 1155.51 & 1156.73 & 1160.08 & 1159.19 & 1160.71 & 1162.60 & 1161.23 \\
\hline \#3 OB & 2182.79 & 2185.30 & 2187.79 & 2189.67 & 2191.79 & 2193.33 & 2195.53 & 2197.02 & 2200.700 & 2198.99 \\
\hline \#4 OB & 1019.86 & 1022.67 & 1022.53 & 1025.94 & 1027.20 & 1029.70 & 1030.78 & 1031.48 & 1032.84 & 1035.59 \\
\hline \#5 OB & 1834.72 & 1835.53 & 1836.91 & 1839.53 & 1842.10 & 1843.97 & 1846.12 & 1849.65 & 1851.31 & 1850.02 \\
\hline \#6 OB & 756.57 & 757.67 & 760.91 & 762.81 & 764.63 & 765.19 & 764.07 & 766.19 & 768.86 & 767.16 \\
\hline \#7 OB & 932.61 & 933.67 & 934.91 & 937.81 & 940.63 & 942.19 & 945.07 & 947.19 & 948.86 & 949.16 \\
\hline$\# 8 \mathrm{OB}$ & 1026.17 & 1028.11 & 1029.41 & 1030.24 & 1032.64 & 1030.75 & 1033.83 & 1036.89 & 1037.12 & 1036.42 \\
\hline$\# 9$ OB & 623.08 & 625.55 & 625.63 & 628.38 & 628.98 & 627.28 & 629.33 & 630.72 & 631.52 & 634.02 \\
\hline \#10 OB & 2140.19 & 2142.55 & 2145.97 & 2145.19 & 2145.84 & 2148.27 & 2150.46 & 2152.06 & 2156.45 & 2154.15 \\
\hline \#11 OB & 797.32 & 798.13 & 797.86 & 799.09 & 798.11 & 797.50 & 797.46 & 797.83 & 798.26 & 797.38 \\
\hline \#12 OB & 1092.27 & 1091.58 & 1092.36 & 1093.40 & 1094.15 & 1093.57 & 1091.76 & 1092.41 & 1093.35 & 1093.17 \\
\hline \#13 OB & 721.16 & 720.82 & 720.38 & 722.18 & 720.53 & 720.86 & 720.95 & 720.47 & 720.58 & 721.17 \\
\hline$\# 1 \mathrm{GH}$ & 1190.34 & 1191.63 & 1193.91 & 1194.36 & 1197.93 & 1202.91 & 1199.83 & 1201.99 & 1198.41 & 1195.82 \\
\hline$\# 2 \mathrm{GH}$ & 616.57 & 617.67 & 620.91 & 619.81 & 620.63 & 625.19 & 624.07 & 626.19 & 628.86 & 627.16 \\
\hline \#3 GH & 232.27 & 232.65 & 233.28 & 234.41 & 236.81 & 235.85 & 236.80 & 237.05 & 238.45 & 237.28 \\
\hline \#4 GH & 970.21 & 972.15 & 973.46 & 973.85 & 974.09 & 974.74 & 975.22 & 975.18 & 974.27 & 973.40 \\
\hline
\end{tabular}

Notes: $p_{i}$ is the forecasted baseline load value of the public building's CAC system in the period of $i$ 
Table A2 Baseline load values of each public building's CAC system before regulation in the evening PLSP on July $30^{\text {th }}$, 2013

\begin{tabular}{|c|c|c|c|c|c|c|}
\hline \multirow[t]{2}{*}{ Building } & \multicolumn{6}{|l|}{$p_{i}(\mathrm{~kW})$} \\
\hline & $i=79$ & $i=80$ & $i=81$ & $i=82$ & $i=83$ & $i=84$ \\
\hline \#1 SM & 1108.40 & 1115.45 & 1121.78 & 1113.91 & 1113.39 & 1107.63 \\
\hline \#2 SM & 1041.98 & 1045.71 & 1050.70 & 1046.64 & 1045.46 & 1042.01 \\
\hline \#3 SM & 863.17 & 870.02 & 875.38 & 871.90 & 866.15 & 861.48 \\
\hline \#4 SM & 1109.57 & 1115.24 & 1118.70 & 1116.92 & 1116.17 & 1108.85 \\
\hline \#5 SM & 1230.00 & 1229.30 & 1228.85 & 1230.16 & 1229.51 & 1229.09 \\
\hline$\# 1 \mathrm{GH}$ & 1235.11 & 1236.41 & 1237.09 & 1236.08 & 1236.68 & 1233.78 \\
\hline \#2 GH & 644.96 & 647.80 & 649.35 & 650.72 & 647.39 & 644.40 \\
\hline \#3 GH & 252.80 & 252.19 & 253.73 & 254.66 & 256.02 & 255.68 \\
\hline \#4 GH & 981.28 & 980.80 & 983.57 & 982.99 & 984.35 & 985.45 \\
\hline
\end{tabular}

\section{References}

[1] Perfumo C, Kofman E, Braslavsky JH et al (2012) Load management: model-based control of aggregate power for populations of thermostatically controlled loads. Energy Convers Manag 55:36-48

[2] Omagari Y, Sugihara H, Tsuji K (2011) A study on demand response effect of thermal storage air-conditioning systems in consideration of electricity market prices. Electr Eng Jpn 176(1):18-27

[3] Cole WJ, Rhodes JD, Gorman W et al (2014) Community-scale residential air conditioning control for effective grid management. Appl Energy 130:428-436

[4] Lin H, Li XH, Cheng PS et al (2014) Thermoeconomic evaluation of air conditioning system with chilled water storage. Energy Convers Manag 85:328-332

[5] Banash S, Fathy HK (2011) Modeling and control insights into demand-side energy management through setpoint control of thermostatic loads. In: Proceedings of the 2011 American Control Conference (ACC'11), San Francisco, CA, USA, 29-1 June-July 2011, pp 4546-4553

[6] Newsham GR, Bowker BG (2010) The effect of utility timevarying pricing and load control strategies on residential summer peak electricity use: a review. Energy Policy 38(7):3289-3296

[7] Upshaw CR, Rhodes JD, Webber ME (2015) Modeling peak load reduction and energy consumption enabled by an integrated thermal energy and water storage system for residential air conditioning systems in Austin, Texas. Energy Build 97:21-32

[8] Newsham GR, Birt BJ, Rowlands IH (2011) A comparison of four methods to evaluate the effect of a utility residential airconditioner load control program on peak electricity use. Energy Policy 39(10):6376-6389

[9] Nghiem TX, Behl M, Mangharam R et al (2012) Scalable scheduling of building control systems for peak demand reduction. In: Proceedings of the 2012 American Control Conference (ACC'12), Montreal, Canada, 27-29 Jun 2012, pp 3050-3055

[10] Xue X, Wang SW, Sun YJ et al (2014) An interactive building power demand management strategy for facilitating smart grid optimization. Appl Energy 116:297-310

[11] Bode JL, Sullivan MJ, Berghman D et al (2013) Incorporating residential AC load control into ancillary service markets: measurement and settlement. Energy Policy 56:175-185

[12] Katipamula S, Lu N (2006) Evaluation of residential HVAC control strategies for demand response programs. In: Proceedings of the 2006 Winter Meeting of American Society of
Heating, Refrigerating and Air-Conditioning Engineers (ASHRAE), Chicago, IL, USA, 21-25 Jan 2006, pp 535-546

[13] Braslavsky JH, Perfumo C, Ward JK (2013) Model-based feedback control of distributed air-conditioning loads for fast demand-side ancillary services. In: Proceedings of the 52nd IEEE Conference on Decision and Control, Florence, Italy, 10-13 Dec 2013, pp 6274-6279

[14] Callaway DS (2009) Tapping the energy storage potential in electric loads to deliver load following and regulation with application to wind energy. Energy Convers Manag 50:13891400

[15] Veldman E, Gibescu M, Slootweg H et al (2013) Scenariobased modelling of future residential electricity demands and assessing their impact on distribution grids. Energy Policy $56: 233-247$

[16] Lu N, Chassin DP, Widergren SE (2005) Modeling uncertainties in aggregated thermostatically controlled loads using a state queueing model. IEEE Trans Power Syst 20(2):725-733

[17] Wang D, Jia HJ, Wang CS et al (2014) Performance evaluation of controlling thermostatically controlled appliances as virtual generators using comfort-constrained state-queueing models. IET Gener Transm Distrib 8(4):591-599

[18] Bashash S, Fathy HK (2013) Modeling and control of aggregate air conditioning loads for robust renewable power management. IEEE Trans Power Syst 21(4):1318-1327

[19] Zhang W, Lian J, Chang C et al (2013) Aggregated modeling and control of air conditioning loads for demand response. IEEE Trans Power Syst 28(4):4655-4664

[20] Cohen A, Wang C (1988) An optimization method for load management scheduling. IEEE Trans Power Syst 3(2):612-618

[21] Chu W, Chen B, Fu C (1993) Scheduling of direct load control to minimize load reduction for a utility suffering from generation shortage. IEEE Trans Power Syst 8(4):1525-1530

[22] Lee T, Cho M, Hsiao Y et al (2008) Optimization and implementation of a load control scheduler using relaxed dynamic programming for large air conditioner loads. IEEE Trans Power Syst 23(2):691-702

[23] Chu CM, Jong TL, Huang YW (2007) Mitigating DLC constraints of air-conditioning loads using a group-DLC method. In: Proceedings of the 2007 IEEE Power and Energy Society General Meeting, Tampa, FL, USA, 24-28 Jun 2007, $6 \mathrm{pp}$

[24] Goel L, Wu Q, Wang P (2010) Fuzzy logic-based direct load control of air conditioning loads considering nodal reliability characteristics in restructured power systems. Electr Power Syst Res 80(1):98-107 
[25] Tindemans SH, Trovato V, Strbac G (2015) Decentralized control of thermostatic loads for flexible demand response. IEEE Trans Control Syst Technol 23(5):1685-1700

[26] Ruiz N, Cobelo I, Oyarzabal J (2009) A direct load control model for virtual power plant management. IEEE Trans Power Syst 24(2):959-966

[27] Huang K, Huang Y (2004) Integrating direct load control with interruptible load management to provide instantaneous reserves for ancillary services. IEEE Trans Power Syst 19(3):1626-1643

[28] Sinitsyn NA, Kundu S, Backhaus S (2013) Safe protocols for generating power pulses with heterogeneous populations of thermostatically controlled loads. Energy Convers Manag 67:297-308

[29] Mehta N, Sinitsyn NA, Backhaus S et al (2014) Safe control of thermostatically controlled loads with installed timers for demand side management. Energy Convers Manag 86:784-791

[30] Turner WJN, Walker IS, Roux J (2015) Peak load reductions: electric load shifting with mechanical pre-cooling of residential buildings with low thermal mass. Energy 82:1057-1067

[31] Perfumo C, Braslavsky JH, Ward JK (2014) Model-based estimation of energy savings in load control events for thermostatically controlled loads. IEEE Trans Smart Grid 5(3):1410-1420

[32] Guillermo E, Isidoro S, Manuel A (2010) Application of an energy management and control system to assess the potential of different control strategies in HVAC systems. Energy Build 42(11):2258-2267

[33] Pan T, Wu SH, Dai EF et al (2013) Estimating the daily global solar radiation spatial distribution from diurnal temperature ranges over the tibetan plateau in China. Appl Energy 107:384-393
[34] Puckett CD, Hennessy TP, Heffner GC et al (2008) Regional approaches to measurement and verification of load management programs. IEEE Trans Power Syst 23(1):204-212

[35] Carrion M, Arroyo JM (2006) A computationally efficient mixed-integer linear formulation for the thermal unit commitment problem. IEEE Trans Power Syst 21(3):1371-1378

Chenxing YANG received B.S. and M.S. in electrical engineering from Jiangsu University, Zhenjiang, China, in 2010 and 2013, respectively. She is currently pursuing the Ph.D. degree in the Department of Electrical Engineering, Southeast University, Nanjing, China. Her research interests include demand side management and control, power system operation and control and smart grids.

Qingshan XU received B.S., M.S. and Ph.D. in electrical engineering from Southeast University, Hohai University and Southeast University, Nanjing, China, in 2000, 2003, and 2006, respectively. Now he is a professor in Electrical Engineering School of Southeast University, Nanjing, China. His research interests include power system operation and control, renewable energy and etc.

Xufang WANG received B.S. in electrical engineering from Shandong University of Technology, Zibo, China, in 2012. She is currently pursuing the M.S. degree in the Department of Electrical Engineering, Southeast University, Nanjing, China. Her research interests include load forecasting and demand side management. 